Ensino, Saúde e Ambiente -V5 (2), pp. 57.68 , ago. 2012

\title{
ESTUDO DE CASO E O CINEMA DE COMÉDIA: MODALIDADE DE METODOLOGIA ATIVA PARA O ENSINO DE DEONTOLOGIA E ÉTICA FARMACÊUTICA
}

\section{CASE STUDY AND COMEDY MOVIE: ACTIVE METHODOLOGIES FOR TEACHING DEONTOLOGY AND FARMACEUTICAL ETHICS}

\author{
Lêda Glicério Mendonça ${ }^{1}$, Lucia de La Rocque ${ }^{2}$, Francisco Romão Ferreira ${ }^{3}$ \\ ${ }^{1}$ Professora de Graduação em Farmácia do Campus Realengo do Instituto Federal de Educação, Ciência e \\ Tecnologia do Rio de Janeiro - IFRJ. Doutoranda do Programa de Ensino em Biociências e Saúde do \\ Instituto Oswaldo Cruz - FIOCRUZ E-mail: leda.mendonca@ifrj.edu.br; \\ ${ }^{2}$ Pesquisadores do Programa de Ensino em Biociências e Saúde do Instituto Oswaldo Cruz - FIOCRUZ. \\ E-mail: luroque@ioc.fiocruz.br; \\ ${ }^{3}$ Pesquisadores do Programa de Ensino em Biociências e Saúde do Instituto Oswaldo Cruz - FIOCRUZ. \\ E-mail: fromao@terra.com.br
}

\section{RESUMO}

Este trabalho consiste no relato de um estudo exploratório para uma pesquisa de Doutorado que abordará o uso de cinema de comédia no ensino de Deontologia Farmacêutica como inspiração para a aplicação de um estudo de caso, modalidade de Metodologia Ativa. A seleção desse tema encontra respaldo na literatura científica nas Diretrizes Curriculares Nacionais da área, embora o enfoque escolhido ainda não tenha sido extensamente explorado. A observação da prática pedagógica seguiu um roteiro previamente desenvolvido e apresentou resultados promissores, o que encorajou à continuidade e o aprofundamento dessa pesquisa.

Palavras-chave: Metodologias Ativas, Pedagogia da Alegria, Ciência\&Arte, Educação Farmacêutica, Comédia

\begin{abstract}
This paper is a report of an exploratory study for a post-graduate research that will broach the use of comic movies as inspiration to employ a case study as a tool to teach Pharmaceutical Deontology. The case study can be considered a kind of active methodology. The choice of this theme can be supported by scientific literature in the National Curriculum Guidelines of this area, although the approach chosen has not been extensively explored. The observation of this pedagogical practice followed a previously developed questionnaire and showed promising results, which encouraged the continuation this research.
\end{abstract}

Keywords: Active Methodologies, Pedagogy of Joy, Art \& Science, Pharmaceutical Education, Comedy 
Ensino, Saúde e Ambiente -V5 (2), pp. 57.68 , ago. 2012

\section{INTRODUÇÃO}

A arte mais importante do mestre é provocar a alegria da ação criadora e do conhecimento (EINSTEIN, 1979:31)-Comment je vois le monde.

O objetivo deste trabalho é discutir como o cinema pode ser utilizado no auxílio do ensino de Deontologia e Ética Farmacêutica. Nesse contexto será explorado o uso de cinema de comédia assumindo o papel de fonte de dados para um estudo de caso, um dos instrumentos da aplicação de metodologias ativas. Oliveira (2010) define a metodologia ativa não como uma teoria única, mas sim como a junção de várias vertentes, influenciadas por várias teorias, oriundas do avanço de pesquisa na área da educação e do ensino. Elege como metodologias ativas melhor padronizadas a aprendizagem baseada em projetos (ABP), a problematização e o estudo de caso. Aqui será relatada a aplicação da técnica do estudo de caso, em que o enredo do filme de comédia foi o caso analisado, discutido e refletido pelos alunos em sala de aula. Essa experiência foi conduzida ao longo do ano letivo de 2011 com 57 alunos de graduação em Farmácia com a intenção de se validar a estratégia de ensino proposta consistindo em uma fase preparatória de uma pesquisa de Doutorado em Ensino em Biociências e Saúde.

A questão central que aqui se apresenta é que a maior parte das aulas de Deontologia, componente obrigatório da matriz curricular da graduação em Farmácia, é ministrada com aula expositiva simples, sem o uso de nenhum recurso didático diferenciado. Por isso, o processo ensino-aprendizagem acaba sendo sofrido e desgastante, levando a um desinteresse e apatia por parte dos alunos. Isso se deve ao fato de que historicamente, a formação dos profissionais das biociências e da saúde apoiou-se em metodologias educacionais tradicionais sob forte influência do mecanicismo de inspiração cartesiana-newtoniana, fragmentado e reducionista. Nesse tocante, houve a compartimentalização do conhecimento em campos altamente especializados, separando-se a razão do conhecimento e a ciência da ética (MITRE et al., 2008).

A Deontologia, ciência que deriva da ética aplicada normativa, e que perpassa todos os campos de atuação do farmacêutico, segundo Zubioli (2004), se ocupa do conjunto de regras que orientam o comportamento de alguém na qualidade de membro de um determinado grupo social, garantindo a conveniência e a utilidade desse grupo, de maneira que ele possa alcançar a melhor finalidade a que se propõe na sociedade.

Pelo fato dessa disciplina não tratar diretamente de conteúdos relacionados à 
produção, controle e dispensação de medicamentos, a maioria dos estudantes não se interessa pela área. Poucos, após a graduação, se aprofundam na prática deontológica, embora seja ela, uma atividade privativa do farmacêutico determinada pelo Decreto Federal 85.878 de 07 de abril de 1981(BRASIL, 1981).

Para alinhavar todas essas questões será utilizada aqui a interseção Ciência\&Arte, mais especificamente o uso de cinema de comédia. Ela pode estimular a criatividade e de maneira mais profunda, conduzir ao pensamento crítico do sujeito. $\mathrm{O}$ gênero comédia foi escolhido pela ação moralizadora que apresenta (CARLSON, 1997). Situações irreais podem provocar reflexões mais leves sobre assuntos mais sérios. Mesmo que a princípio a apropriação da comédia para discutir questões éticas e deontológicas seja inusitada, Moliére na construção de suas comédias de costumes já declarava que "o dever da comédia é corrigir os homens divertindo-os" (LEAL, 2006). Georges Syders (1996), pedagogo francês, preconiza a transposição didática da alegria que consiste em passar da alegria/não-alegria da cultura para a alegria/não-alegria da cultura dentro das condições escolares, conjugando as manifestações artísticas ligadas ao lazer, tais como a música, o teatro e o cinema. Por isso, o uso do cinema de comédia, nesse contexto, pode ser entendido como uma escolha que reúne tanto as Metodologias Ativas, como a Pedagogia da Alegria proposta por Snyders (1995)

\footnotetext{
Na confluência da valorização do aluno pelo professor e do desejo de cultura peculiar do aluno, ambição deste de ser considerado como sujeito verdadeiro e não como receptáculo a ser preenchido com as palavras do mestre ou as frases de um livro; oferecer aos alunos a alegria de serem ativos, de se saberem ativos (p.118).
}

Esses dados encorajaram a escolha pelo uso de filmes de comédia para o ensino pelo fato do gênero ser inusitado para trazer à tona discussões tão áridas e ao mesmo tempo ter boa aceitação pelo público alvo. Outro fato importante é que até o momento não foram encontrados registros de trabalhos científicos que abordassem especificamente o uso do gênero comédia para fomentar discussões sobre Deontologia e ética. Os trabalhos que se apresentam usam em sua maioria o drama, a ficção-científica ou citam apenas o uso do cinema (BLASCO et al., 2005 e 2006; DIEZ, 2005; LENAHAN e SHAPIRO, 2005; LOSCOS et al. 2006; TAPAJÓS 2007; SIQUEIRABATISTA et al., 2008) sem se deter a algum gênero específico da sétima arte. Sendo assim, a comédia pode representar uma ação educativa e moralizadora. 
Ensino, Saúde e Ambiente -V5 (2), pp. 57.68 , ago. 2012

\section{METODOLOGIAS ATIVAS PARA O ENSINO DE DEONTOLOGIA E ÉTICA FARMACÊUTICA}

A Farmácia é compreendida pela CAPES (Coordenação de Aperfeiçoamento de Pessoal de Nível Superior) como Ciência da Saúde. Entretanto, diferente de outros profissionais da Saúde, o foco do farmacêutico é o medicamento. Durante sua graduação é enfatizada a aprendizagem das técnicas de fabricação, controle de qualidade e dispensação de medicamentos. Essa formação tecnicista influencia na predileção dos alunos pelas disciplinas tecnológicas em detrimento das humanísticas, tais como a Deontologia e Ética Farmacêutica. Entretanto, no exercício da profissão, o farmacêutico depara-se com situações que envolvem debates éticos e deontológicos, que, em decorrência dessa característica curricular, nem sempre estão preparados a perceber e resolver.

A Deontologia, ciência que deriva da ética aplicada normativa, e que perpassa todos os campos de atuação do farmacêutico, estuda o conjunto de regras que orientam o comportamento de alguém na qualidade de membro de um determinado grupo social, garantindo a conveniência e a utilidade desse grupo, de maneira que ele possa alcançar a melhor finalidade a que se propõe na sociedade. $\mathrm{O}$ ensino das questões éticas e deontológicas no currículo da Farmácia no Brasil foi iniciado em 1925, inserido na disciplina intitulada "Higiene Social". Na reforma curricular de 1962 a Deontologia e Ética ganhou espaço próprio. No ano de 1969 ela passa a integrar o elenco de disciplinas de formação profissional obrigatória, fato que dura até hoje (ZUBIOLI, 2004). As atuais Diretrizes Curriculares Nacionais do Curso de Graduação em Farmácia (BRASIL, 2002) preconizam o perfil farmacêutico, com formação geral, humanística, crítica e reflexiva. Por isso, o processo ensino-aprendizagem da Dentologia não deve se restringir apenas à exposição e conhecimento das normas legais e ao cumprimento do código de ética do profissional, mas também à reflexão sobre essas regras, suas justificações e seus fundamentos (DURAND, 2003).

$\mathrm{Na}$ área da saúde, a discussão sobre o uso de metodologias ativas de aprendizagem se faz presente na literatura internacional desde a década de 1960. Mesmo que a tendência tenha se iniciado no ensino médico, a metodologia é válida e deve ser estimulada em todas as outras profissões da saúde, bem como nas ciências sociais e nas exatas (GOMES, 2010). Cecy (2011) afirma que as Diretrizes Curriculares Nacionais do Curso de Graduação em Farmácia estabelecem que o ensino deva ser 
centrado no estudante e apoiado no professor como facilitador e mediador do processo de ensino-aprendizagem, característica principal das metodologias ativas. Oliveira (2010) destaca, ainda, que as estratégias de ensino que preenchem o formato do método ativo devem ser caracterizadas por: a) promover a aprendizagem significativa; b) serem colaborativas (em grupo); c) interdisciplinares (integradas); d) contextualizadas (reais); e) reflexivas (valores éticos); f) críticas; g) investigativas (aprender a aprender); h) humanísticas (social); i) motivadoras (emoção); j) desafiadoras. Na atual perspectiva será utilizada a técnica do estudo de caso, no qual o enredo do filme de comédia será o caso analisado, discutido e refletido pelos alunos em sala de aula.

O método do Estudo de Casos é uma variante do método Aprendizado Baseado em Problemas ou Aprendizado Centrado em Problemas, também conhecido como Problem Based Learning (PBL). Sá e Queiroz (2009) conduziram uma pesquisa detalhada sobre a aplicação do estudo de caso para o ensino de ciências, mais especificamente no ensino de química e o definem como:

utilização de narrativas sobre dilemas vivenciados por pessoas que necessitam tomar uma decisão importante a respeito de determinadas questões. Tais narrativas são chamadas casos. A familiarização com o contexto do caso e com seus personagens impulsiona os estudantes na busca de escolhas e posterior tomada de decisão, necessária para a sua solução... há autores que assumem que qualquer descrição de eventos utilizável para favorecer o aprendizado seja um caso. (p.12)

Esses autores enfatizam que vários materiais podem atuar como fontes para criar um estudo de caso, tais como artigos de divulgação científica, artigos originais de pesquisa ou filmes comercias, situação abordada neste trabalho.

\section{DESENVOLVIMENTO, APLICAÇÃO E VALIDAÇÃO DA ESTRATÉGIA DE ENSINO}

Este trabalho consistiu em um estudo preparatório para uma pesquisa de Doutorado em Ensino em Biociências e Saúde que tem como proposta o uso de filmes de comédia como estratégia de ensino de Deontologia e Ética Farmacêutica em substituição à prova convencional. A prática pedagógica foi sucedida da aplicação de um questionário (exposto no Apêndice I) para a validação da adequabilidade da estratégia de ensino.

Os sujeitos envolvidos foram 57 alunos no decorrer do ano de 2011 regularmente matriculados na disciplina de Deontologia e Ética Farmacêutica, 
Ensino, Saúde e Ambiente -V5 (2), pp. 57.68 , ago. 2012

componente curricular obrigatório do quarto período do curso de graduação em Farmácia do Campus Realengo do Instituto Federal de Educação, Ciência e Tecnologia do Rio de Janeiro - IFRJ. Foi distribuído a todos os alunos um Termo de Consentimento Livre e Esclarecido e explicado que o procedimento fazia parte de uma pesquisa e que responder ao questionário seria opcional. Por isso, apenas 24 alunos responderam.

A estratégia aqui proposta foi a análise de filmes de comédia que seguiram roteiros sistematizados. Os filmes pré-selecionados foram: "O inventor da mocidade" (1952); "O professor aloprado" (1963) e (1996); "Junior" (1994); "Sem sentido" (1998) e "Fórmula 51" (2001). A escolha desses títulos não foi por acaso. O enredo desses filmes tem correlação com os temas mais relevantes da disciplina, tais como: conduta ética do profissional que pesquisa medicamentos, registro de medicamentos, experimentação com seres humanos, limites legais de atuação do profissional (atribuições profissionais privativas e não privativas), conflito de interesses na pesquisa, uso racional de medicamentos, além de outros questionamentos sobre a ação farmacológica que cada droga testada em cada filme ocasiona sobre o voluntário.

O desenvolvimento da estratégia seguiu os seguintes passos:

1. Aulas expositivas, em que se abordaram os fundamentos da Deontologia precederam a atividade;

2. Os alunos foram orientados a se distribuírem em grupos para assistir aos filmes emprestados pela professora em mídia DVD original em momento extraclasse e analisá-los de acordo com o roteiro sistematizado. Cada grupo assistiu a um filme, de maneira que os títulos não se repetissem na mesma turma;

3. Após assistirem o filme, os alunos debateram e analisaram o caso exposto pelo enredo. Cada grupo preparou uma apresentação de seus resultados para expor ao restante da turma.

O roteiro de análise foi o mesmo para todos os filmes e foi o que se segue:

\section{ROTEIRO PARA ANÁLISE DE FILMES EM DEONTOLOGIA}

ATENÇÃO: atividade tem um momento em grupo e um momento individual.

Momento em grupo: Assistir ao filme. Debater o filme para localizar os itens pedidos. Apresentar em sala de aula o enredo do filme e os pontos levantados pelo grupo. 
Momento individual: Análise individual, por escrito seguindo o modelo abaixo. A análise deverá ser feita à luz dos assuntos abordados ao longo do semestre na disciplina "Deontologia e Legislação Farmacêutica". Atente para o fato que não existem personagens farmacêuticos nos enredos apresentados, por isso sua correlação será por aproximação e comparação. Sempre que for pedida justificativa para a sua resposta será necessário buscar e citar "entre aspas" o(s) dispositivo(s) legais que comprovem suas afirmações. Siga o roteiro abaixo para conduzir sua análise. O seu texto pode ser livre, porém será necessário atender as questões abaixo expostas.

1. Nome do filme e ano.

2. Aponte e comente uma passagem no filme, que em sua opinião seja imoral.

3. Você considera que as atividades técnico-científicas desenvolvidas pelo cientista retratado no filme seriam de competência do Farmacêutico? Justifique sua resposta.

4. Aponte, comente e justifique um momento do filme em que você pôde perceber correlação em cada um dos seguintes itens: a) Código de Ética do Profissional Farmacêutico; b) Infrações e penalidades sanitárias; c) Normas relativas à ética na pesquisa com seres humanos; d) Normas relativas à ética na pesquisa com animais; e) Normas de propaganda de produtos para saúde. (Uma situação para cada item)

5. Aponte, comente e justifique uma passagem no filme que se relacione com a Portaria MS/SVS 344 de 1998.

6. A droga testada no filme é inovadora, genérica ou similar? Justifique sua resposta. Como proceder para regularizá-la?

7. Aponte e comente uma passagem no filme que apresente uma imprecisão científica, de acordo com as Ciências Farmacêuticas (qualquer ramo das ciências farmacêuticasfora da Deontologia). Fundamente sua resposta com a citação da literatura pertinente.

Um questionário para a avaliação da adequabilidade dos filmes foi aplicado ao final da estratégia de ensino. Como a participação era voluntária, apenas 24 alunos de um total de 57 responderam ao questionário. As questões referentes à caracterização dos sujeitos da pesquisa informaram que o grupo de respondentes era constituído de 8 homens e 16 mulheres com a predominância de sujeitos entre 18 e 23 anos (vinte alunos). Os demais alunos tinham mais de 23 anos (Perguntas 1 e 2 do questionário).

As perguntas 3 e 4 procuraram apurar o interesse dos alunos quanto à disciplina e ao gênero cinematográfico escolhido para a prática pedagógica e estão representados nos gráficos 1 e 2 


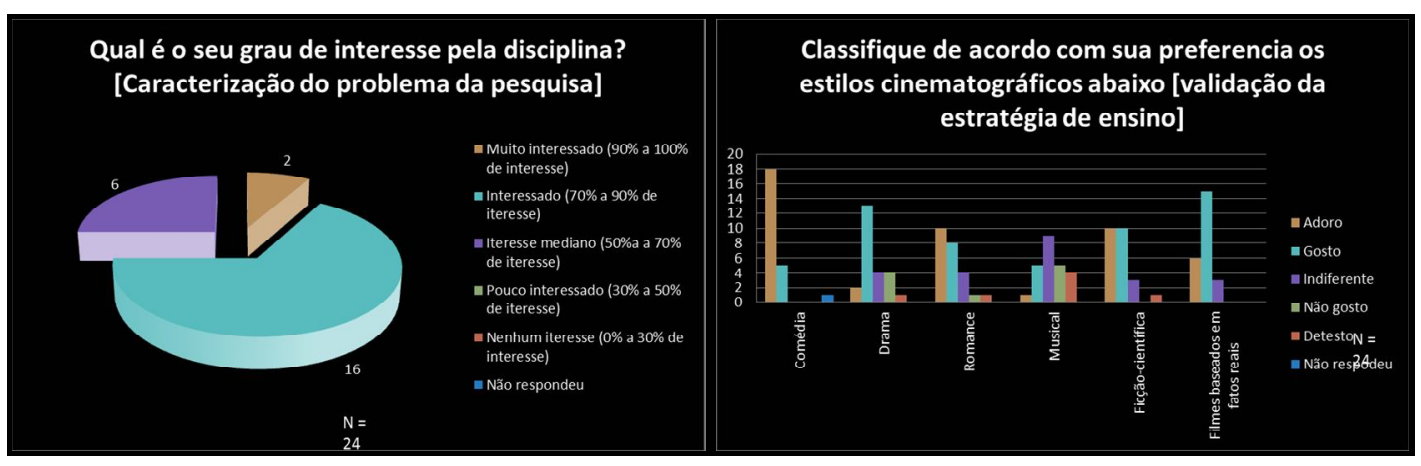

Gráfico 1: Resposta da questão 3

Gráfico 2: Resposta da questão 5

Optou-se por retirar a pergunta 3 na versão final do questionário, pois, como o instrumento é aplicado pela professora da disciplina, os alunos poderiam se sentir constrangidos em responder que não se interessam pelo tema. Esse dado é confirmado pelas respostas registradas na questão 7, comentada a seguir. A resposta tabulada na questão 5, que trata sobre a preferência dos respondentes quanto ao estilo cinematográfico, revelou que a escolha pela comédia foi acertada, não só pela empatia do público alvo, mas também por referencias teóricos já pesquisados previamente:

se traçarmos um círculo em torno das ações e intenções que comprometem a vida individual ou social e que se castigam a si mesmas por suas consequências naturais, restará ainda do lado de fora desse terreno de emoção e luta, numa zona neutra na qual o homem se apresenta simplesmente como espetáculo ao homem, certa rigidez de corpo, do espírito, d caráter, que a sociedade quereria ainda eliminar para obter dos seus membros a maior elasticidade e a mais alta sociabilidade possíveis. Essa rigidez é o cômico, e a correção dela é o riso (Berguson, 1980:19)

O que implica que os professores, a instituição universitária como um todo clamem, proclamem e compreendam que a Universidade, além de seu papel inelutável de preparação dos jovens para uma vida profissional bastante próxima, para uma vida plenamente adulta bastante próxima, tenha a vocação de ser durante esses poucos anos um lugar destinado à alegria cultural (Snyders, 1995:15)

As questões objetivas quanto à adequabilidade da proposta pedagógica são expostas na tabela 1

Tabela 1: Respostas das questões 4, 6, 7, 8 e 9

\begin{tabular}{|c|c|c|c|}
\hline Perguntas obje tivas do questionário & Sim & Não & $\begin{array}{c}\text { Não } \\
\text { respondeu }\end{array}$ \\
\hline 4 -Você gosta de cinema? & 23 & 1 & 0 \\
\hline $\begin{array}{c}\text { 6 -Você acha que o uso de cinema facilitou a sua aprendizagem? } \\
\text { proposto da disciplina? }\end{array}$ & 22 & 0 & 2 \\
\hline 7 -Você acha que o uso de cinema aumentou o seu interessa na disciplina? & 22 & 2 & 0 \\
\hline $\begin{array}{c}\text { 9 -Você achou válido utilizar essa estratégia de ensino com uso de cinema de comédia } \\
\text { como alternativa para sua avaliação no lugar de uma prova convencional? }\end{array}$ & 24 & 0 & 0 \\
\hline
\end{tabular}


Apenas um respondente disse que não gostava de cinema, a maioria achou que o uso do cinema de comédia facilitou o entendimento dos conteúdos da Deontologia. Os dois alunos que responderam que o uso de cinema não aumentou o seu interesse na disciplina, são os mesmo que declararam ter um grande interesse pela disciplina (Pergunta 3 - alunos com muito interesse na disciplina - de 90 a 100\%). Os demais declararam que a prática fez aumentar seu interesse pelos temas da Deontologia, o que faz levar em consideração que nem todos os alunos que responderam ter interesse nessa temática na questão 3, se sentiram realmente à vontade para responder livremente sobre esse assunto. A questão 9 tratou sobre o fato de se assumir essa prática pedagógica em substituição a prova convencional. Todos acharam válida a proposta e em relatos coletados surgiram manifestações em relação ao fato da análise do filme promover o senso crítico e proporcionar situações em que o estudante se via encorajado a se aprofundar nos estudos para solucionar os problemas apresentados. Esse resultado é corroborado por referenciais teóricos das Metodologias Ativas

\footnotetext{
Quando se trabalha com metodologias ativas, desaparece o modelo onde o professor é o centro das atenções. Surge um modelo baseado na aprendizagem onde o estudante é o principal ator do processo. Aprendizagem abrange um processo de crescimento e desenvolvimento da pessoa em sua totalidade (...). Esta preocupação de formar estudante como um todo ("formação profissional, pessoal e social") exige uma mudança significativa na educação superior da área da saúde que, historicamente, possui um forte enfoque tecnicista. A aprendizagem de ciências humanas e sociais exige uma abertura para o debate, para a reflexão, para novas teorias e ideias (...) além de uma mudança profunda da avaliação da aprendizagem (Oliveira, 2010:15)
}

Dessa forma, o uso do cinema de comédia pode ser utilizado como inspiração para a preparação de um estudo de caso, modalidade de metodologia ativa, e utilizado em substituição às avaliações de aprendizagem convencional.

\section{CONSIDERAÇÕES FINAIS}

Os resultados aqui apresentados deste estudo exploratório indicaram que a escolha da utilização do cinema de comédia para o ensino da Deontologia e Ética Farmacêutica pode apresentar resultados promissores. Essa proposta pedagógica encontra fundamentação teórica nos campos da Metodologia Ativa, da Pedagogia da Alegria e nas atuais Diretrizes Curriculares Nacionais da Graduação em Farmácia, além de ter sido bem aceita em um momento de experimentação em sala de aula. Já existem registros da utilização de enredos de filmes comerciais para promover o estudo de caso, 
modalidade de metodologia ativa. A transformação do ambiente educacional em um local que torne a aprendizagem agradável, levando o aluno à alegria de aprender também encontra respaldo na literatura, porém até onde sabemos, não foram encontrados registros sobre pesquisas aplicadas ao uso de cinema de comédia no ensino das Ciências Farmacêuticas, e tampouco sobre a interseção da Pedagogia da Alegria com as Metodologias Ativas, o que pode ser um diferencial neste estudo. Portanto, a relevância deste trabalho, repousa não somente no aspecto instrumental do uso do cinema de comédia como aporte para o ensino de Deontologia, mas também no de proporcionar uma oportunidade para aprofundar essa temática ao longo de uma pesquisa de Doutorado.

\section{REFERÊNCIAS}

BERGSON, H. O riso: ensaio sobre a significação do cômico. Rio de Janeiro: Zahar Editores, 1980: 105p.

BLASCO, G.P; GALLIAN, D.M.C; RONCOLETTA, A.F.T; MORETO, G. Cinema para o estudante de medicina: um recurso afetivo / efetivo na educação humanística. Revista Brasileira de Educação Médica. Mai-Ago. 2005. V.29, n. 2: p119-128.

BRASIL. Casa Civil. Decreto n. 85.878 de 7 de abril de 1981. Estabelece normas para execução de Lei n. 3.820, de 11 de novembro de 1960, sobre o exercício da profissão de farmacêutico, e dá outras providências. Diário Oficial da República Federativa do Brasil. Brasília DF, 9 abr. 1981. Disponível em: http://www.mp.ba.gov.br/atuacao/ceacon/legislacao/farmacia/decreto_85878_1981.pdf Acesso em: 22 out. 2010.

BRASIL. Ministério da Educação. Secretaria de Educação Superior. Resolução n. 2 de 19 de fevereiro de 2002. Institui Diretrizes Curriculares Nacionais do Curso de Graduação em Farmácia. Diário Oficial da República Federativa do Brasil, seção 1, p.9. Brasília DF, 4 mar. 202. Disponível em: <portal.mec.gov.br/cne/arquivos/pdf/CP022002.pdf>. Acesso em: 25 out. 2010.

CARLSON, M. Teorias do Teatro: estudo histórico-crítico, dos gregos à atualidade. São Paulo: Fundação Editora da UNESP, 1997.

CECY, C. A formação humanística e social do farmacêutico: um diferencial da qualidade. In: Melhoria da qualidade em educação farmacêutica. Organizadores: CECY, C.; OLIVEIRA, G.A.; COSTA, E.M.M.B. Brasília: Abenfarbio; 2011.

DIEZ, K.S; PLEBAN, F.T; WOOD, R.J. Lights, camera, action: interacting popular film in the classroom. Journal Scholar Health, v. 75, n.7: p. 271-275. Set. 2005.

DURAND, G. Introdução geral à Bioética: história, conceitos e instrumentos. 2. Ed, São Paulo: Loyola, 2003.

GOMES, M.P.C, ET AL. O uso de metodologias ativas no ensino de graduação nas ciências sociais e da saúde - avaliação dos estudantes. Ciência \& Educação, v. 16, n. 1, p. 181-198, 2010. 
LEAL, E. A. "É uma estranha empresa fazer rir as pessoas honestas": a arte de fazer comédia para Moliére a partir da peça teatral Don Juan. Revista de Historia e estudos culturais.V.3.n4. Ano III (2006). Disponível em:<

http://www.revistafenix.pro.br/PDF9/7.Artigo.Eliane_Leal.pdf >. Aceso em: 08 set 2011.

LENAHAN, P; SHAPIRO, J. Facilitating the emotional education of medical students: using literature and film in training about intimate partner violence. Family Medicine. Set. 2005, v. 37, n.8: p. 543-545.

LOSCOS, J; BAÑOS, J.E; LOSCOS, F. Medicine, cinema and literature: A teaching experiment at the Universitat Autónoma de Barcelona. Journal of Medicine and Movies. Out. 2006, v. 2: p. 138-142.

MENDONÇA, L.G. Uso de Cinema e Teatro: Desenvolvimento de roteiros de Estratégias de Ensino de Boas Práticas de Fabricação na Graduação em Química. Dissertação de Mestrado Profissional apresentada ao Programa de Ensino em Biociências e Saúde. Instituto Oswaldo Cruz. FIOCRUZ. 2010.

MITRE, S. M. et al . Metodologias ativas de ensino-aprendizagem na formação profissional em saúde: debates atuais. Ciências e saúde coletiva, Rio de Janeiro, 2011. Disponível em: <http://www.scielosp.org/scielo.php?script=sci_arttext\&pid=S141381232008000900018\&lng=en\&nrm=iso>. Acesso em 23 Jun 2011.

OLIVEIRA, G.A. Uso de metodologias ativas em Educação Superior. In: Metodologias Ativas: aplicações e vivências em Educação Farmacêutica. Organizadores: CECY, C.; OLIVEIRA, G. A.; COSTA, E.M.M.B. Brasília: Abenfarbio; 2010.

SÁ, L.P.; QUEIROZ, S.L. Estudo de casos no ensino de química. Campinas, SP: Editora Átomo. 2009: p. 95.

SIQUEIRA-BATISTA, R; GOMES, A.P; RÔÇAS, G; LEITE, S.Q.M; SIQUEIRABATISTA, R. O cinema na formação bioética de professores de Ciências. In: I ENEC: Encontro Nacional de Ensino de Ciências da Saúde, 2008; Niterói, Anais de evento, p. 15-17. Disponível em: <http://www.unipli.com.br/mestrado/img/conteudo/ANAISENEC_VERSÃfÆ'O\%20FINAL(3).pdf>. Acesso 12 set. 2008.

SNYDERS, G. Feliz na Universidade: estudo a partir de algumas biografias. São Paulo: Paz e Terra. 1995. 189p.

. Alunos felizes: reflexão sobre a alegria na escola a partir de textos literários. São Paulo: Paz e Terra. 1996. 2 ed. 204p.

TAPAJÓS R. A comunicação de notícias ruins e a pragmática da comunicação humana: o uso do cinema em atividades de ensino/aprendizagem na educação médica. Interface comunicação em saúde e educação. 2007 Jan-Abr;11(21):165-172.

ZUBIOLI, A. Ética Farmacêutica: Direito, ética e Deontologia. São Paulo:Sobravime, 2004. 


\section{APÊNDICE I - Tabulação do questionário aplicado no estudo.}

\begin{tabular}{|c|c|c|c|c|c|}
\hline Pergunta & \multicolumn{5}{|c|}{ Alunos respondentes } \\
\hline \multicolumn{2}{|l|}{1 - Qual é o seu sexo? [Caracterização dos sujeitos da pesquisa] } & & \\
\hline Masculino & 8 & & & & \\
\hline Feminino & 16 & & & & \\
\hline \multicolumn{2}{|l|}{2 - Qual é a sua faixa etária? [Caracterização dos sujeitos da pesquisa] } & & & & \\
\hline \multicolumn{2}{|l|}{ Menos de 18 anos } & & & & \\
\hline De 18 a 23 anos & 20 & & & & \\
\hline Mais de 23 aos & 4 & & & & \\
\hline \multicolumn{2}{|l|}{$\begin{array}{l}3 \text { - Qual é o seu grau de interesse pela disciplina? [Caracterização do } \\
\text { problema da pesquisa] }\end{array}$} & & & & \\
\hline Muito interessado ( $90 \%$ a $100 \%$ de interesse) & 2 & & & & \\
\hline Interessado (70\% a 90\% de iteresse) & 16 & & & & \\
\hline Iteresse mediano (50\%a a $70 \%$ de iteres se) & 6 & & & & \\
\hline \multicolumn{2}{|l|}{ Pouco interessado (30\% a 50\% de iteresse) } & & & & \\
\hline \multicolumn{2}{|l|}{ Nenhum iteresse (0\% a 30\% de interesse) } & & & & \\
\hline \multicolumn{2}{|l|}{4 - Você gos ta de cinema? [Validação da es tratégia de ensino] } & & & & \\
\hline Sim & 23 & & & & \\
\hline Não & 1 & & & & \\
\hline \multirow[t]{2}{*}{$\begin{array}{l}\text { - Classifique de acordo com sua preferencia os estilos cinematográficos } \\
\text { abaixo [validação da es tratégia de ensino] }\end{array}$} & & & & & \\
\hline & Adoro & Gosto & Indiferente & Não gos to & Detesto \\
\hline Comédia & 18 & 5 & & & \\
\hline Drama & 2 & 13 & 4 & 4 & 1 \\
\hline Romance & 10 & 8 & 4 & 1 & 1 \\
\hline Musical & 1 & 5 & 9 & 5 & 4 \\
\hline Ficção-científica & 10 & 10 & 3 & & 1 \\
\hline Filmes baseados em fatos reais & 6 & 15 & 3 & & \\
\hline Policial & 1 & & & & \\
\hline Épico & 1 & & & & \\
\hline Terror & 1 & & & & 1 \\
\hline Suspense & 4 & & & & \\
\hline Desenho animado/animação & 1 & & & & \\
\hline Religioso & 1 & & & & \\
\hline \multicolumn{2}{|l|}{$\begin{array}{l}6 \text { - Você acha que o uso de cinema facilitou a sua aprendizagem? [Validação } \\
\text { da es tratégia de ensino] }\end{array}$} & & & & \\
\hline Sim & 22 & & & & \\
\hline \multicolumn{2}{|l|}{ Não } & & & & \\
\hline Não respodeu & 2 & & & & \\
\hline \multicolumn{2}{|l|}{$\begin{array}{l}7 \text { - Você acha que o uso de cinema aumentou o seu interessa na disciplina? } \\
\text { [Validação da es tratégia de ensino] }\end{array}$} & & & & \\
\hline Sim & 22 & & & & \\
\hline Não & 2 & & & & \\
\hline \multicolumn{2}{|l|}{$\begin{array}{l}8 \text { - Você achou que o filme utilizado em sala de aula cons eguiu abordar o } \\
\text { conteúdo propos to da disciplina? [Validação da es tratégia de ensino] }\end{array}$} & & & & \\
\hline Sim & 23 & & & & \\
\hline 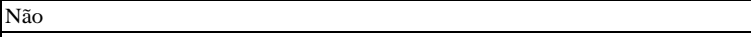 & 1 & & & & \\
\hline \multicolumn{2}{|l|}{$\begin{array}{l}9 \text {-Você achou válido utilizar essa estratégia de ensino com uso de cinema de } \\
\text { comédia como alternativa para sua avaliação no lugar de uma prova } \\
\text { convencional? [Validação da es tratégia de ensino] }\end{array}$} & & & & \\
\hline Sim & 24 & & & & \\
\hline \multicolumn{2}{|l|}{ Não } & & & & \\
\hline \multicolumn{2}{|l|}{$\begin{array}{l}10 \text { - Na sua observação, qual é a formação do cientista que conduz a pes quisa } \\
\text { com medicamentos no filme que você assistiu? [caracterização da identidade } \\
\text { do cientista] }\end{array}$} & & & & \\
\hline Químico & 11 & & & & \\
\hline Farmacêutico & 4 & & & & \\
\hline Médico & 6 & & & & \\
\hline Biomédico & 1 & & & & \\
\hline Biólogo & 1 & & & & \\
\hline Professor de genética & 1 & & & & \\
\hline \multirow[t]{2}{*}{$\begin{array}{l}11 \text { - O que levou você a identificar a formação do cientis ta do filme as sis tido? } \\
\text { [caracterização da identidade do cientista] }\end{array}$} & & & & & \\
\hline & Químico & Farmacêutico & Médico & Biomédico & Biólogo \\
\hline A formação dele foi informada claramente no filme & 6 & & 5 & & \\
\hline Deduzi sua formação pelo contexto do filme & 4 & 1 & 1 & 1 & 1 \\
\hline Estou convicto de que a atribuição é de competência desse profissional & & 3 & & & \\
\hline Outro & 1 & & & & \\
\hline
\end{tabular}

